\title{
PREDICTION OF DIFFICULT AIRWAY : COMPARISON BETWEEN INDIVIDUAL PREDICTOR WITH COMBINATION OF PRE-OPERATIVE PREDICTORS.
}

\section{Anaesthesiology}

Dr Abid Banavasi $\quad$ Sr. Resident, Department OfAnaesthesia, Yenepoya Medical College, Mangalore.

\section{Dr. Habib}

Rahaman A A*

Professor, Department Of Anaesthesia, Yenepoya Medical College, Mangalore. *Correponding Author

\section{Dr. Harish Hegde \\ Prof \& HOD, Department Of Anaesthesia, Yenepoya Medical College, Mangalore.}

\section{ABSTRACT}

Background and Aims: Inability to intubate trachea is one of the most important cause of Anaesthesia related mortality and hypoxic brain injury. Various pre-operative tests were devised for prediction of difficult intubation but have variable positive predictive value, sensitivity and specificity. We aimed to compare the commonly used predictive tests Modified Mallampati test, Thyromental Distance and Neck circumference to assess the predict difficult intubation, individually and in combination.

Material and Methods: 115 adult patients of ASA $1 \& 2$ undergoing elective general surgical procedures under general anaesthesia with endotracheal intubation in a Medical College Hospital were the subjects in this study. Patients airway were assessed by modified Mallampati test, neck circumference and thyromental distance. Patients in whom fibre optic intubation was planned were excluded. Difficulty in Intubation was assessed by Cormack and Lehane's grading. Which is the gold standard to assess difficulty in intubation.

Results: Modified Mallampati Test has specificity of $61.54 \%$ and Sensitivity of $86.14 \%$.

Thyromental Distance has a specificity of $61.54 \%$ and Sensitivity $42.57 \%$. Neck circumference has a specificity of $15.38 \%$ and Sensitivity of $100 \%$. When all the three tests combined specificity increased to $82.3 \%$ and Sensitivity increased to $100 \%$.

Conclusion: By combining the three p predictors we can increase the sensitivity and specificity of prediction there by reducing false arms about difficult intubation and increase the true positive difficult intubation so that advanced airway management equipments can be kept ready.

\section{KEYWORDS}

Airway Assessment, Difficult Airway, Predictive Tests, Modified Mallampatti Test, Thyromental Distance, Cormack Lehane Grading

\section{INTRODUCTION}

Even in the wake of recent advances in the field of anaesthesiology, anaesthetists all around the world face an ageless problem- "The difficult airway".'. In spite of the various tools one has in his arsenal, the preoperative detection of a possible difficult airway is of prime importance

The ASA closed claims database analysis of adverse respiratory events has found that vast majority of $85 \%$ airway related events involves brain damage or death, and as many as $1 / 3 \mathrm{rd}$ of deaths is attributed solely to anaesthesia due to inability to maintain patent airway

Securing the airway is the primary responsibility of the Anaesthsesiologist ${ }^{4}$. Inspite of advances in Airway management Inability to intubate the trachea using routine gadgets is a clinical reality $^{5}$. Advanced airway management equipment may not be available in every operation theatre ${ }^{6}$. Hence, assessment to anticipate difficulty in intubation is very important. If the cases of difficult airway could be predicted confidently in the period, the anaesthesiologist can plan the safest and most effective way of managing tracheal intubation by Specialised airway devices

Most commonly used assessment tools are Modified Mallampati test ${ }^{3}$, which compares the relative size of the tongue with the pharyngeal size $^{4}$. Thyromental distance which gives an estimation of Mandibular space and Neck circumference which is a marker for deposition of subcutaneous fat in the upper body".

Tracheal intubation, most commonly performed using a direct laryngoscopy technique, is the gold standard in securing the airway and is considered mandatory in a variety of patient populations and operations $^{8}$. The Cormack-Lehane (CL) classification is a grading system commonly used to describe laryngeal view during direct laryngoscopy has become the gold standard for airway classification in clinical practice and in airway-related research ${ }^{11}$. Grade I and Grade II are considered easy intubation and Grade 3 and 4 are considered as Difficult intubation ${ }^{1}$

Many a times assessment of airway using the Modified Mallampati test $^{3}$, Thyromental distance or Neck circumference alone can result in false negative prediction and one can end up with cannot Intubate Cannot Oxygenate situation ${ }^{12}$. Hence, we did a study to know whether combining these three predictive tests together can accurately predict difficulty in intubation.

\section{Material and Methods :}

115 adult patients of ASA $1 \& 2$ undergoing elective general surgical procedures under general anaesthesia with endotracheal intubation in a Medical College Hospital were the subjects in this study. Patients airway were assessed by modified Mallampati test, neck circumference and thyromental distance. Patients in whom fibre optic intubation was planned were excluded.

\section{Modified Mallampati Test ${ }^{(9,12,18,26}$}

It is done by examiner sitting in front of the patient ${ }^{6}$, who should be sitting up with head in neutral position and the patient is asked to open their mouth maximally and protrude the tongue without phonating and Mallampati grading is done accordingly.

\begin{tabular}{|l|l|}
\hline Grade 1 & $\begin{array}{l}\text { Visualization of soft palate, fauces, uvula, anterior and } \\
\text { posterior pillars. }\end{array}$ \\
\hline Grade 2 & Visualization of soft palate, fauces and uvula. \\
\hline Grade 3 & Visualization of soft palate and base of uvula. \\
\hline Grade 4 & Only hard palate is visible, soft palate not visible at all. \\
\hline
\end{tabular}

Grades 3 and 4 are classified as predictors of difficult intubations.

\section{Assessment Of Airway Using Thyromental Distance ${ }^{(9,18,20)}$}

Done using a measuring tape from the mentum of the mandible to thyroid notch in the midline with neck in full extension. Measurement of less than $6 \mathrm{cms}$ is considered to be predictor of difficult intubation.

\section{Assessment Of Airway Using Neck Circumference ${ }^{(18,21,22)}$}

Done using a measuring tape from thyroid notch to middle of neck in the neutral neck position. Measurements of more than $45 \mathrm{~cm}$ are considered to be a predictor of difficult intubation.

On the day of Surgery after inducing the patient as per hospital protocol, Laryngoscopy was done by a senior anaesthesiologist 3 minutes after the administration of Vecuronium Bromide and Cormac and Lehane grading was done and patient was intubated.

Grade 3 and 4 were considered as difficult intubation.

Submitted : $27^{\text {th }}$ August, 2019

Accepted : $2^{\text {nd }}$ November, 2019

Publication : 01 ${ }^{\text {st }}$ December, 2019 


\section{ETHICAL CLEARANCE}

Study was started after getting ethical clearance committee and procedures followed were in accordance with the Ethical Standards of Yenepoya University Ethics Committee.

\section{STATISTICALANALYSIS:}

Analysis is performed using SPSS Version 22.

RESULTS:

The following methods of statistical analysis have been used in this study. The data were entered into a Microsoft Excel Worksheet and analyzed using SPSS (version 22) statistical package.

The sensitivity and specificity of Mallampatti Grade predictor, Neck circumference Grade predictor and Thyromental distance Grade Predictor and Mallampatti + Neck circumference +Thyromental distance, compared to the Cormack and Lehane Grading were determined. In addition to sensitivity and specificity, the positive predictive value and negative predictive values were calculated.

Table 1 : Mallampati Scoring

\begin{tabular}{|l|c|c|c|}
\hline \multicolumn{2}{|c|}{ Mallampatti scoring } & Frequency & Percent \\
\hline Valid & G1 & 9 & 7.9 \\
\hline & G2 & 83 & 72.8 \\
\hline & G3 & 22 & 19.3 \\
\hline & Total & 114 & 100.0 \\
\hline
\end{tabular}

Table 3 . Specificity, Sensitivity, PPV and NPV of Different Groups

\begin{tabular}{|l|l|l|l|l|}
\hline & Sensitivity & Specificity & PPV & NPV \\
\hline MPT & $86.14 \%$ & $61.54 \%$ & $94.57 \%$ & $36.60 \%$ \\
\hline NC & $100 \%$ & $15.38 \%$ & $90.18 \%$ & $100 \%$ \\
\hline TMD & $42.57 \%$ & $61.54 \%$ & $89.58 \%$ & $12.12 \%$ \\
\hline
\end{tabular}

\section{DISCUSSION}

The significance of difficult or failed tracheal intubation following induction is a well recognized cause of morbidity and mortality in anaesthetic practice. Moreover the need to predict potentially difficult tracheal intubation has received wide attention. Based on these observations and studies, our study was conducted to overcome a few of these limitations and hence we have used three simple bed side airway assessment tests i.e., Mallampati test and measurement of thyromental distance and neck circumference to predict the incidence of difficult intubation.

The study population consisted of 115 ASA grade $1 \& 2$ patients with apparently normal airway who underwent surgical procedures under general anesthesia. In our study the prediction of difficult intubation was done by combining Mallampati test grade $3 \& 4$ and thyromental distance $<6 \mathrm{~cm}$ and neck circumference $>45 \mathrm{~cm}$, during the preoperative airway assessment and correlating it with the Cormack \& Lehane laryngoscopic grading at intubation. Grade $3 \& 4$ of Cormack \& Lehane was considered difficult intubation.

We also analysed the three test in combination/parallel and calculated the predictive power of these tests in assessing DVL. In such a combination, if any one of the test shows difficult intubation, we take it as predictor of DVL. We found out that two tests in combination showed increased sensitivity and negative predictive value than when they are done alone. Also we found out that the combination of Modified Mallampati Test and Neck Circumference showed high sensitivity $(90 \%)$, specificity $(55.5 \%)$, positive predictive value $(92.5 \%)$, negative predictive value $(75.5 \%)$ and accuracy $(86.84 \%)$, when compared to other test done in combination. Thus we conclude that the combination of Modified Mallampati Test and Neck Circumference is the best to predict DVL.

\section{SUMMARYAND CONCLUSION :}

Unanticipated Difficult Visualization of Larynx (DVL) is still one of the dreadful challenges faced by the anesthetists around the world. DVL is a major cause of mortality and morbidity in the practice of anaesthesiology. In our study the incidence of DVL was $11.4 \%$. We arrived at the conclusion that when done in isolation, out of three tests the Neck circumference Test predicted DVL with more accuracy.

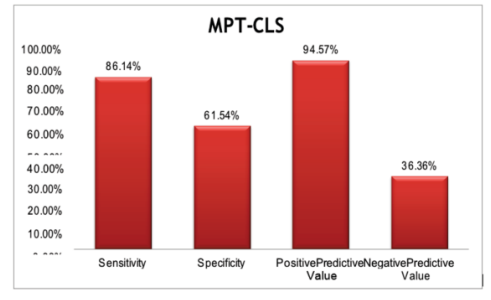

Graph: 1 (Mallampati Test Specificity, Sensitivity, PPV and NPV)

Table 2: TMD Thyromental category

\begin{tabular}{|c|c|c|c|c|c|}
\hline & & Frequency & Percent & Valid Percent & Cumulative Percent \\
\hline Valid & Difficult & 66 & 57.9 & 57.9 & 57.9 \\
\hline & Easy & 48 & 42.1 & 42.1 & 100.0 \\
\hline & Total & 114 & 100.0 & 100.0 & \\
\hline
\end{tabular}

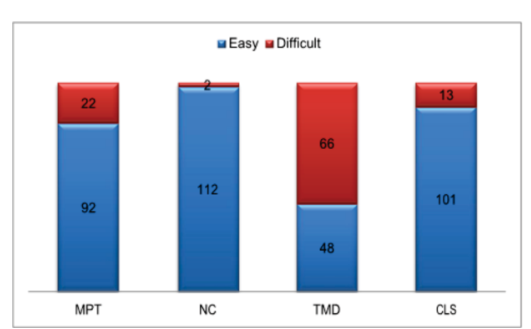

Graph 2 ; Comparison Between MPT, NC, TMD and CLS

\begin{tabular}{|l|l|l|}
\hline Gold Standard & Chi-square test(p- value) & Accuracy In percentage \\
\hline CLS & $<.001^{*}$ & 83.33 \\
CLS & $<.001^{*}$ & 90.35 \\
\hline CLS & .777 & 44.74 \\
\hline
\end{tabular}

Also performing these tests in parallel increased the sensitivity and negative predictive significantly than when they are done alone. Also we found that the combination of Modified Mallampati Test and Neck circumference is the best predictor of DVL

The above result shows that the discriminative power is greater in combination of tests than when used alone. The patients with difficult airway determined by Cormack and Lehane grade $3 \& 4$ were intubated either by "BURP" manuver or bougie. The airway management was not associated with any patient morbidity or mortality, Further, surgery was never cancelled nor postponed due to difficulties with airway management.

\section{Acknowlwdgement: None}

Funding: None

\section{Conflict of Interest: None}

\section{REFERENCES}

1. Lundstorm L H, Anderson V M, Moller A M, Charuluxananan S, Hermits L and Wetterslev. J. Poor prognostics value of the modified mallampati score-a meta-analysis involving 177088 patients. British Journal of Anesthesia 2011;107(5):659-667.

2. Adamus M, Fritscherova S, Hrabalek L, Gabrhelik T, Zapletalova J, Janout J. Mallampati test as a predictor of laryngoscopic view. Biomedical papers of the Medical Faculty of the University Palacky, Olomouc, Czechosolvakia 2010;154(4):339-344.

3. Noorizad S and Mahdian. M. Mallampati and thyromental distance to predict difficul intubation. Journal of Medical Sciences 2006;6(2): 169-172.

4. Diaz E O, Rioss J J A, Diaz J LA and Aguirre J M O. Predictive factors of difficult airway with known assessment scale. Cirugia Y Cirujanos 2010;78(5):393-399.

5. Shiga T, Wajima Z, Inoue T, Sakamoto A. Predicting difficult in intubation apparently normal patients - a meta analysis of bedside screening test performance. American Society of Anesthesiology 2005;103:429-437.

6. ASA task force on management of difficult airway practice guidelines for managemen of the difficult airway Anaesthesiology 1993;78:597-602

7. Caplan RA, Posner K L, Ward R J et al : Adverse respiratory events in anaesthesia : A closed claims analysis : Anaeshesiology 72;828:1990.

8. Miller CG: Management of the difficult intubation in closed malpractice claims 1: ASA news letter. 2000;64(6):13-16and19.

9. Benumof JL, Management of the difficult adult airway with special emphasis on awake tracheal intubation Anaesthesiology 1991;75:1087 1110.

10. Largeron O, Masson E, Haraux C, Guggiari M, Biareli A, C oriat P, Riou B, difficult tracheal intubation and mask ventilation. Anaesthesia 2000;92:1229-1235.

11. Shiga Toshiya et.al. 2005 "Predicting difficult intubation in apparently normal patients, A meta-analysis of bedside screening test performance". Anesthesiology 1995;103:42937.74

12. Mallampatti SR, Gatt SP et.al. "A clinical sign to predict difficult tracheal intubation: prospective study". Can Anaesth soc j 1985;32:429-34. 
13. Jansenns M, Harstein G;Management of difficult intubation; Eur J Anaesthesiology 2001;183-12.

14. Wilson ME, Spiegelhalter D, Robertson JA, Lesser P, Predicting difficult intubation. British journal of Anaesthesia 1988;61:211-6.

15. Atkinson RS, Rushman GB, Alfred lee J; A synopsis anaesthesia 10th edition, Indian edition, K M Varghese company; 1987;203-205.

16. Ellis H, Feldman S; Anatomy for anaesthetists, 8th edition, Blackwell publishing 2004;26-42.

17. Romans GJ, Cunningham manual of pratical anatomy, 15 th edition, 1986; vol3:135-170.

18. Benumof J, Airway management principal and practice. St lowis MO; Mosby year book 1996;121-143

19. Oates JDC, Macload A, Dostes DA, Persall PJ. Comparison of 2 method for predicting 102 difficult intubation. British journal of Anaesthesia 1991;66:305-309

20. Mallampatti SR, Clinical sign to predict tracheal intubation (hypothesis). Canadian journal of Anaesthesia 1983;30:316-317

21. G Metcalf. Anaesthetic implication of temparo mandibular joint disease Canadian journal of Anaesthesia 1993;39:610 -616.

22. Mcintyrejoor the difficult tracheal intubation. Canadian journal of Anaesthesia 1987;39:204-213.

23. Chou H.C, Wu T. L, Mandibulohyoid distance in difficult laryngoscopy. British journal of Anaesthesia 1993;71:335-339.

24. David J, stone \& Thomas J, GAL Airway management in Miller RD Anaesthesia, Churchill living stone, New York. 5th edition, 2000; vol1: 1414-1457.

25. Juvin $\mathrm{P}$, Lavaut E, Dupont $\mathrm{H}$, Lefervre $\mathrm{P}$, et al; Difficult tracheal intubation is more common in obese than in lean patients. Anesth. Analg .2003;97:595-600.

26. King TA, Adams AP Failed intubation, British journal of Anaesthesia 1990;65:400414.75

27. Morgan $\mathrm{M}$, Anaesthesia contribution to maternal mortality. British journal of Anaesthesia. 1987;59:842-855.

28. Collin Vincent J. Principal of Aneasthesiology. General and regional Anaesthesia 3rd edition. philadelphia;1993;460-564.

29. Fahey MR, Morris RB, Miller RD et al, Clinical pharmacology of ORG NC 45(Norcuron); A new non depolarising muscle relaxant. Anaesthesiology 1981;(55)6.

30. Agoston S, Salt P, Newton D et al; The neuro muscular blocking action of ORG NC 45, A new pancuronium derivative in anaesthetized patients; A pilot study. British journal of anaesthesia 1980;52:53s

31. Miller RD, Rupp SR; Clinical pharmacology of vecuronium and atracurium. Anaesthesiology 1984;61:444.

32. Morris RB, Cahalan MK, Miller RD et al; The cardiovascular effects of vecuronium $(\mathrm{O} \backslash \mathrm{RG} \mathrm{NC} 45)$ and pancuronium in patients undergoing coronary artery by pass grafting. Anaesthesiology 1983;58:438.

33. Tullock WC, Diana P, Cook DR et al; Neuro muscular and cardio vascular effects of high-dose vecuronium. Anesth Analg 1990;70:86.

34. Mol WE, Fokkema GN; Mechanism for the hepatic uptake of organic cation; studies with the muscle relaxant vecuronium in islated rat hepatocytes. J Pharmacology Exp Ther 1988:244:268.

35. Bencini AF, Scaf AHJ, Sohn YJ et al; Disposition and urinary excertion of vecuronium bromide in anaesthetized patients with normal renal function or renal failure. Anesth Analg 1986;65:245.

36. Bencini AF, Mol WEM; Uptake and excretion vecuronium bromide and pancuronium bromide in the isolated perfused rat liver. Anaesthesiology 1988;69:487.

37. Caldwell JE, Szenohradszky J; The pharmaco dynamics and pharmacokinetics of the metabolite 3-desacetylvecuronium(ORG7268) and its parent compound, vecuronium, in human volunteers. J Pharmacol Exp Ther 1994:270:1216.

38. Segrado V, Caldwell JE, Persistent paralysis in critically ill patients after long-term Segrado V, Caldwell JE, Persistent paralysis in critically ill pat

39. Fisher DM, Castaagnoli K, Miller RD, Kinectics and Dynamics of vecuronium in anesthetized infants and children. Clin Pharmacol Ther 1985;37:402

40. Fisher DM, Castagnoli K, Miller RD; Vecuronium kinetics and dynamics in anesthetized infants and children. Clin Pharmacol Ther 1985;37:402

41. Fisher DM, Miller RD; Neuromuscular effects of vecuronium (ORG NC 45) in infants and children during N2O, halothane anaesthesia. Anaesthesiology 1983;58:519.

42. Cormack RS, Lehane J: "Difficult tracheal intubation in obstetrics". Anaesthesia 1984;39:1105-11.

43. Ayoub C, Baraka A, et.al. "A new cut-off point of thyromental distance for prediction of difficult airway". Middle East J Anesthesiol 2000;15:619-33.

44. Frerk CM: "Predicting difficult intubation". Anaesthesia 1991; 46:1005-8.

45. Iohom G, Ronayne M, et.al. "Prediction of difficult tracheal intubation". Eur J Anaesthesiol 2003;20:31-6

46. Wong SH, Hung CT: "Prevalence and prediction of difficult intubation in Chinese women."Anaesth Intensive Care 1999;27:49-52.94

47. Butler PJ, Dhara SS; Prediction of difficult laryngoscopy; An assessment of the thyromental distance and mallampatti predictive tests; Anaesth Intensive care 1992;20:139-42

48. Bilgin H, Ozyurt G: Screening test for predicting difficult intubations :a clinical assessment in Turkish patients. Anaesth Intensive care 1998; 26:382-6.

49. Koh LK, Kong CE, Ip-Yam PC; The modified Cormack \& Lehane score for the grading of direct laryngoscopy; Evaluation in the Asian population. Anaesth Intensive care 2002;30:48 -51.

50. Ita CE, Eshict AI, A kapan, SG: Recognition of difficult airway in normal Nigerian adults (a prospective study). West Afr J Med 1994; 13:102-104

51. Tse JC, Rimm EB, Hussain A: Predicting endotracheal intubation in surgical patients scheduled for general anaesthesia:a prospective blind study. Anaesth Analg 1995;81:254-8.

52. Ulrich B, Listyo R, Gerig HJ, et al; The value of BURP and 3 predictive tests of difficult intubation. Anaesthestsist 1998;47:45.77

53. Benumof J L, Cooper SD; Quantative improvement in laryngoscopic view by optimal external laryngeal manipulation. J Clin Anaesth 1996;8:136

54. Ezri T, Medalion B, Weisenberg M, Szmuk P, Warters RD, Charuzi I; Increased body mass index per se is not a predictor of difficult laryngoscopy; Canadian journal of Anaesthesia 2003; 50; 179-83

55. Vani V, Kamath SK, Naik L, The palm print as a sensitive predictor of difficult laryngoscopy in diabetics; A comparison with other airway evaluation indices. J postgrad Med 2000; 46:75-9.

56. Lundstorm L H, Anderson V M, Moller A M, Charuluxananan S, Hermits L and Wetterslev J. Poor prognostics value of the modified mallampati score-a meta-analysis involving 177088 patients. British Journal of Anesthesia 2011;107(5):659-667.

57. Adamus M, Fritscherova S, Hrabalek L, Gabrhelik T, Zapletalova J, Janout J. Mallampati test as a predictor of laryngoscopic view. Biomedical papers of the Medical Faculty of the University Palacky, Olomouc, Czechosolvakia 2010;154(4):339-344

58. Noorizad $\mathrm{S}$ and Mahdian. M. Mallampati and thyromental distance to predict difficult intubation. Journal of Medical Sciences 2006;6(2): 169-172.

59. Diaz E O, Rioss J JA, Diaz J L A and Aguirre J M O. Predictive factors of difficult airway with known assessment scale. Cirugia Y Cirujanos 2010;78(5):393-399.
60. Shiga T, Wajima Z, Inoue T, Sakamoto A. Predicting difficult in intubation apparently normal patients-a meta analysis of bedside screening test performance. American Society of Anesthesiology 2005;103:429-437. 